\title{
Correction to: Investigation on the effect of cottonseed oil blended with different percentages of octanol and suspended MWCNT nanoparticles on diesel engine characteristics
}

\author{
Manzoore Elahi M. Soudagar ${ }^{1}$. Asif Afzal ${ }^{2} \cdot$ Mohammad Reza Safaei $^{3,4,5} \cdot$ A. Muthu Manokar ${ }^{6}$. Ahmed I. EL-Seesy ${ }^{7}$ \\ M. A. Mujtaba ${ }^{1}$. Olusegun David Samuel ${ }^{8} \cdot$ Irfan Anjum Badruddin ${ }^{9,10} \cdot$ Waqar Ahmed $^{1} \cdot$ Kiran Shahapurkar $^{11}$. \\ Marjan Goodarzi ${ }^{12}$
}

Published online: 20 November 2020

(c) Akadémiai Kiadó, Budapest, Hungary 2020

\section{Correction to: Journal of Thermal Analysis and Calorimetry https://doi.org/10.1007/s10973-020-10293-x}

In the original publication of the article, the affiliations of the third, fourth and fifth authors were incorrectly published. The corrected affiliation is given in this correction article. The spelling of tenth author name was published erroneously. The corrected spelling of the author is given in the author group above. The original article has been corrected.
Publisher's Note Springer Nature remains neutral with regard to jurisdictional claims in published maps and institutional affiliations.

The original article can be found online at https://doi.org/10.1007/ s10973-020-10293-x.

Mohammad Reza Safaei

mohammadrezasafaei@duytan.edu.vn

1 Department of Mechanical Engineering, Faculty of Engineering, University of Malaya, 50603 Kuala Lumpur, Malaysia

2 Department of Mechanical Engineering, P. A. College of Engineering (Affiliated to Visvesvaraya Technological University Belagavi), Mangaluru 574153, India

3 Institute of Research and Development, Duy Tan University, Da Nang 550000, Vietnam

4 Faculty of Electrical-Electronic Engineering, Duy Tan University, Da Nang 550000, Vietnam

5 NAAM Research Group, Department of Mathematics, Faculty of Science, King Abdulaziz University, P.O. Box 80259, Jeddah, Saudi Arabia

6 Department of Mechanical Engineering, B. S. Abdur Rahman Crescent Institute of Science and Technology, Vandalur, Tamil Nadu 600048, India

7 Department of Mechanical Engineering, Benha Faculty of Engineering, Benha University, Benha 13512, Qalubia, Egypt
8 Department of Mechanical Engineering, Federal University of Petroleum Resources, PMB 1221, Efurun, Delta State, Nigeria

9 Research Center for Advanced Materials Science (RCAMS), King Khalid University, P.O. Box 9004, Abha 61413, Asir, Kingdom of Saudi Arabia

10 Mechanical Engineering Department, College of Engineering, King Khalid University, Abha 61413, Asir, Kingdom of Saudi Arabia

11 Department of Design and Manufacturing Engineering, School of Mechanical, Chemical and Materials Engineering, Adama Science and Technology University, 1888 Adama, Ethiopia

12 Sustainable Management of Natural Resources and Environment Research Group, Faculty of Environment and Labour Safety, Ton Duc Thang University, Ho Chi Minh City, Vietnam 